\title{
INFLUÊNCIA INSTITUCIONAL EM ARRANJOS PRODUTIVOS LOCAIS PARA CRIAÇÃO DE INOVAÇÃO
}

\section{RESUMO}

Enquanto políticas governamentais e regulatórias podem promover mudanças significativas em tecnologias de produtos e processos, que por sua vez beneficiam inovadores industriais, se não forem cuidadosamente administradas podem gerar importantes efeitos deletérios no processo inovativo (Patanakul \& Pinto, 2014). Tomando por base esse pressuposto, esta pesquisa teve por objetivo evidenciar o papel chave das instituições no processo de criação e difusão de inovação principalmente no âmbito de setores com baixo dinamismo tecnológico. Para tal, foram utilizados dados tabulados pela Pintec (2013) sobre os setores de confecções e de indústria alimentícia no estado do Ceará, Brasil. Partindo de um modelo em que foram privilegiadas as dimensões mercadológicas e de perfil de utilização tecnológica naqueles setores, observou-se que o referido modelo não explicava de forma completa o processo de criação e difusão tecnológica. Foi então acrescentada uma nova dimensão ao modelo considerando o papel institucional de apoio ao processo inovativo, adquirindo então o novo arcabouço metodológico para uma melhor capacidade explicativa dos fenômenos envolvidos.

Palavras-chave: Clusters; Inovação; Instituições; Recursos Estratégicos; Pintec.

\section{INFLUENCE INSTITUTIONAL ARRANGEMENTS IN PRODUCTION SITES FOR INNOVATION}

\section{CREATION}

\begin{abstract}
While government and regulatory policies can promote significant changes in product technologies and processes, which in turn benefit industrial innovative, if not carefully managed can generate significant deleterious effects on the innovation process (Patanakul \& Pinto, 2014). Based on this assumption, this research objectived to highlight the key role of institutions in the process of creation and innovation diffusion in particularly within sectors with low technological dynamism. To this end, we used the data tabulated by Pintec (2013) on the clothing and food industries in the state of Ceará. Brazil. Starting from a model in which we focused on the marketing and technological usage profile dimensions in those sectors, it was observed that the model did not explain fully the creation and technology diffusion process. Then added a new dimension to the model considering the institutional role in supporting the innovation process, so getting the new methodological framework for better explanatory power of the phenomena involved.
\end{abstract}

Key words: Clusters. Innovation; Institutions; Strategic Resources; Pintec 


\section{INFLUENCIA INSTITUCIONALIDAD EN LUGARES DE PRODUCCIÓN DE LA CREACIÓN DE INNOVACIONES}

\section{RESUMEN}

Si bien las políticas gubernamentales y reguladoras pueden promover cambios significativos en las tecnologías de productos y procesos, que a su vez se benefician industrial innovadora, si no se maneja con cuidado puede generar efectos nocivos significativos en el proceso de innovación (Patanakul y Pinto, 2014). Sobre la base de esta hipótesis, este estudio tuvo como objetivo poner de relieve el papel fundamental de las instituciones en el proceso de creación y difusión de la innovación principalmente en sectores de bajo dinamismo tecnológico. Para esto, se utilizaron los datos tabulados por Pintec (2013) en el sector de la confección y la industria alimentaria en el estado de Ceará, Brasil. A partir de un modelo en el que nos hemos centrado el perfil de uso dimensiones de marketing y tecnología en esos sectores, se observó que el modelo no explica por completo el proceso de difusión creación y la tecnología. A continuación, se añade una nueva dimensión al modelo teniendo en cuenta el papel institucional en el apoyo al proceso de innovación, por lo que la adquisición de nuevo marco metodológico para una mejor capacidad explicativa de los fenómenos implicados.

Palabras clave: Clusters; La Innovación; Instituciones; Los Recursos Estratégicos; Pintec.

Oscar Sarquis González Braga ${ }^{1}$ Sérgio Henrique Arruda Cavalcante Forte ${ }^{2}$

\footnotetext{
${ }^{1}$ MBA em Gestão de Empresas pela Fundação Getúlio Vargas - FGV. Brasil. E-mail: oscarsarquis@uol.com.br

${ }^{2}$ Doutor em Administração de Empresas pela Fundação Getúlio Vargas - FGV. Professor da Universidade de Fortaleza

- UNIFOR. Brasil. E-mail: sergioforte@unifor.br
} 


\section{INTRODUÇÃO}

Em tempos recentes, dado o crescimento da economia mundial, estimulada pelo incremento do nível de comércio e a brutal pressão sobre os recursos existentes, os espaços econômicos tornaram-se cenários de adensamento de competitividade. A procura por posições competitivas vantajosas das firmas nas diversas indústrias tem sido objeto de estudo constante na literatura sobre estratégia empresarial, com ênfase sobre as fontes das referidas vantagens. As diferentes abordagens concentram suas discussões sobre a estrutura mercadológica em que se inserem as firmas, e na existência de recursos especiais dentro que justifiquem seus desempenhos diferenciados (Mascena, Figueiredo \& Boaventura, 2013).

Do ponto de vista da estrutura mercadológica, a existência de clusters, entendidos como concentrações geográficas de firmas de um determinado setor ou indústria, tem sido largamente estudada em função da influência que tais arranjos exercem no desempenho das unidades produtivas que deles participam e também no desenvolvimento das localidades onde se encontram (Porter, 1998). Esse processo é resultado de uma melhoria geral da produtividade do sistema associada a esse tipo de organização produtiva, mais ainda que em outros tipos de organizações baseadas na integração vertical ou em vínculos sistêmicos horizontais encontrados na cadeia de valor das empresas de uma determinada indústria. Porter (1998) sumariza que os clusters modificam a produtividade, por meio do acesso a insumos e trabalhadores especializados; a informação sobre o processo produtivo; e o mercado associado à indústria em que atua, com a existência de complementaridades, ao acesso às instituições e aos bens públicos governamentais ou privados locais, e aos incentivos à padronização e ao acompanhamento do desempenho da totalidade do setor.

Ademais, a participação das firmas em clusters é estratégica para todas as firmas, independentemente de seu tamanho, sendo que para as empresas de pequeno porte em regiões pouco desenvolvidas, tornase fundamental (Cassiolato \& Lastres, 2003).

Por outro lado, recursos especiais inerentes às firmas são fontes de vantagem competitiva sustentável. Para possuírem esse potencial, esses recursos devem incorporar quatro atributos: 1) devem ser valiosos, posto que exploram oportunidades e ou neutralizam fraquezas, aumentando a rentabilidade da firma e ou reduzindo seus custos operacionais; 2) devem ser raros entre os competidores atuais e potenciais; 3 ) devem ser imperfeitamente imitáveis ou inimitáveis; e d) devem ser passíveis de exploração pelos processos organizacionais da firma (Barney, 1991). Em relação à sustentabilidade da posição competitiva vantajosa, considerados os demais atributos como atendidos, somente poderá ser alcançada se os recursos em questão não puderem ser replicados ou substituídos, por três razões: 1) a habilidade de uma firma obter e utilizar um recurso é dependente de suas condições históricas únicas; 2) o vínculo entre os recursos possuídos por uma firma e a vantagem competitiva sustentável é causalmente ambíguo; e 3) os recursos que geram a vantagem da firma são socialmente complexos. O processo de inovação, criação de tecnologia e o seu uso produtivo necessitam de recursos socialmente complexos (Barney, 1991).

$\mathrm{Na}$ mesma direção de Barney (1991), considerando a perspectiva dos sistemas setoriais de inovação, Malerba (1999) observa que o processo de inovação estratégica possui como elementos chaves o mecanismo de aprendizado das firmas, suas competências, comportamentos e a organização, bem como a complexa rede de aprendizado e colaboração da firma estabelecida socialmente.

O modelo de Silvestre e Dalcol (2007) bem exemplifica a postura analítica vigente com ênfase sobre essas duas abordagens, utilizando-se de um arcabouço teórico em que o dinamismo do processo inovativo fundamenta-se em duas dimensões: as estruturas das conexões de conhecimento, relacionadas à estrutura de cluster (Bell \& Albu, 1999), e a postura das firmas em relação à tecnologia utilizada, relacionada à abordagem de sistemas de inovação (Freeman, 1995). Silvestre e Dalcol (2007) objetivaram demonstrar que o dinamismo inovativo das firmas constituintes do arranjo produtivo petrolífero da Bacia de Campos, no Rio de Janeiro está diretamente relacionado aos níveis de integração interno e externo ao cluster das firmas, bem como à forma específica de produção, utilização e difusão de tecnologia por estas firmas.

Ocorre que apesar das influências acima consideradas serem relevantes na explicação da posição competitiva empresarial preconiza-se que elas não são suficientes para a elaboração do modelo explicativo. Uma terceira abordagem objetiva complementá-lo. Diz respeito ao papel do ambiente institucional na promoção do desempenho empresarial. Malerba (1999) observa que agentes conhecidos como organizações "extra firma" (non-firm organization) tais como universidades, instituições de financiamento, governo, autoridades locais suportam de várias maneiras a difusão de novas tecnologias dentro de um sistema setorial.

Instituições entendidas como agentes do setor público (Link\& Scott, 2010) exercem um preeminente papel na promoção e sustentação da inovação, atuando como condutores fundamentais da saúde das economias locais, particularmente quando são ativamente suportadas pela atuação de agências governamentais. Fornecem a oportunidade para a transformação tecnológica e o desenvolvimento sustentável por meio do estabelecimento de padrões e metas de política claras, atuando de maneira flexível para permitir que as firmas utilizem estratégias específicas para atingirem as referidas metas (Ashford, 2000; Bossink, 2002). Adicionalmente, a atuação direta 
em pesquisa e desenvolvimento, incentivos tributários para investimento em tecnologias sustentáveis, além de outras iniciativas de apoio técnico podem criar um ambiente de negócio favorável. Este, por sua vez ajuda a promover e sustentar práticas inovativas e por conseguinte, o desenvolvimento de toda a indústria (Nelson \& Rosenberg, 1993; Porter, 1998).

Diante desta contextualização, esta pesquisa visa responder ao seguinte problema: em que medida o modelo de Silvestre e Dalcol (2007) explica o processo inovativo em arranjos produtivos locais utilizando somente as duas dimensões daquele modelo híbrido?

Como objetivo geral a pesquisa investiga a influência institucional para a criação de inovação e a modificação do perfil de utilização da tecnologia.

Como objetivo específico, propõe um arcabouço teórico modificado sobre o modelo híbrido proposto por Silvestre e Dalcol (2007).

O papel de governo é necessário para o progresso econômico, mas pode não ser suficiente, principalmente no âmbito de economias pouco dinâmicas ou que necessitem de apoio complementar. Segundo Peng et al.(2009), há duas premissas básicas que explicam o comportamento racional dos indivíduos e firmas frente ao seu ambiente institucional: a primeira salienta que suas escolhas estratégicas são tomadas levando em consideração as restrições de um arcabouço institucional dado; a segunda salienta que nos casos em que as restrições formais não são muito claras ou são fracas, tomam lugar outras informais. Isso é mais verdadeiro em indústrias pouco dinâmicas ou imaturas.

As discussões sobre a relevância do papel institucional para o desenvolvimento das iniciativas de inovação têm obtido crescente atenção por parte da comunidade acadêmica mundial, tomando por base os sistemas de inovação, conforme já discutido (Ashford, 2000; Bossink, 2002; Link\& Scott, 2010; Malerba, 1999). No Brasil, o tema tem sido abordado de forma segregada com ênfase sobre as influências mercadológicas ou mesmo sobre os sistemas de inovação. A análise da influência combinada desses fatores com o importante papel institucional não tem recebido o mesmo foco (Mazzucato, 2013). É sobre essa lacuna que o trabalho foi desenvolvido. A partir de sua conclusão, espera-se uma atuação mais decisiva por parte do setor público para o incentivo à inovação.

O trabalho explora a teoria que embasa a discussão institucional, o suporte simultâneo ao processo inovativo por parte das estruturas de mercado, dos sistemas setoriais de inovação e das instituições. Posteriormente, a partir de uma visão crítica sobre os modelos existentes, elabora um arcabouço teórico e o utiliza para a análise do processo inovativo em setores industriais existentes, tomando por base os dados fornecidos pela Pesquisa de Inovação [PINTEC] do Instituto Brasileiro de Geografia Estatística [IBGE] (Pintec, 2013).

\section{ABORDAGEM TEÓRICA}

\subsection{Discussão Institucional}

No dizer de Peng et al.(2009), toda disciplina é unificada por um conjunto de questões fundamentais que agem para definir um campo e orientar a atenção dos interessados naquele ramo disciplinar. As teorias que versam sobre estratégia competitiva tendem a ser agrupadas conforme respondem a quatro perguntaschaves no que concerne às escolhas estratégicas.

Em primeiro lugar preocupam-se em como as firmas diferem umas das outras. Na visão baseada na indústria, representada por Porter (1998), essa questão é definida inteiramente pela estrutura industrial, a partir da posição relativa das firmas em relação às suas cinco forças competitivas (compradores, fornecedores, rivais, entrantes potenciais e substitutos). A visão baseada em recursos representada por Barney (1991) afirma que são os recursos especiais das firmas em mercados imperfeitos que as diferenciam. As duas visões negligenciam o contexto que em as firmas operam, aceitando-o meramente como modulador competitivo.

Ocorre que DiMaggio e Powell (1983) já observavam que essa visão geral da indústria induz à ideia deque as firmas operando em um mesmo ambiente institucional tendem a ser similares, no âmbito do que denominaram de isomorfismo institucional. Pode-se distinguir nesse processo alguns mecanismos isomórficos específicos, quais sejam, o isomorfismo coercitivo, que provém da influência política e do problema da legitimidade; o isomorfismo mimético, que resulta de respostas padrão à incerteza, considerando que a incerteza também é uma força poderosa que estimula a imitação; e o isomorfismo normativo, associado à profissionalização, entendida como um mecanismo coletivo dos membros de uma ocupação em que as condições e os métodos de seu trabalho são definidos para controlar a produção dos produtores e de estabelecer uma base e legitimação cognitivas para sua autonomia ocupacional. Nesse âmbito, as universidades e redes profissionais criam um pool de indivíduos quase intercambiáveis.

A utilização do processo inovativo como mecanismo de fuga do isomorfismo advém da necessidade das organizações em ambientes hipercompetitivos, no sentido denotado por D'Aveni (1994), de se destacarem em um processo de diferenciação contínua que produz vantagem competitiva sustentável. Assim, empresas concorrentes ao identificarem uma organização inovadora passam então a observar as ações empreendidas por essa empresa e a copiá-las, tendo por objetivo desfazer a posição competitiva vantajosa. Segue-se, então, que esse mecanismo se repete, até que a líder inovativa não consiga mais ocupar a posição de destaque em decorrência da primeira inovação, o que, naturalmente, provoca diminuição do desempenho competitivo. Para recuperar a posição anterior, a líder precisa novamente desenvolver esforço inovativo. Enquanto a força 
isomórfica impele as empresas à similaridade e à semelhança, o processo inovativo promove a diferenciação e a reformulação dos padrões competitivos (Souza, 2013). Por conseguinte, elas devem considerar o estímulo ao processo inovativo por parte das instituições como mecanismo evolutivo primário do campo organizacional.

Observando estritamente as indústrias em economias emergentes, quanto mais desenvolvidas forem as instituições formais que suportam as relações de mercado, mais essa realidade se evidencia. Por outro lado, quanto mais importantes forem as redes de relacionamento informal, e quanto mais relevantes forem as instituições informais que ali operam, as diferenças tendem a se acentuarem (Peng et al., 2009).

Outra pergunta norteadora das teorias sobre estratégia empresarial foca sobre a maneira como as firmas se comportam em relação aos seus objetivos estratégicos. A visão baseada em indústria propõe que a tarefa estratégica objetiva, principalmente, a ocupação de posições que são menos vulneráveis relativamente às cinco forças dentro de uma indústria. $\mathrm{Da}$ mesma forma, a busca de criação $\mathrm{e}$ desenvolvimento de recursos e capacidades específicas que estabeleçam vantagem competitiva para as firmas é o objetivo precípuo da visão baseada em recursos para a tarefa estratégica (Barney, 1991). Para a visão baseada em instituições no tripé estratégico de Peng et al. (2009), em seu comportamento estratégico, as firmas precisam levar em conta as influências das regras do jogo institucional, sejam formais e informais, que reduzem os riscos e aumentam o nível de informação da indústria. $\mathrm{O}$ próprio processo inovativo é cercado por inúmeras incertezas, por prazos longos de desenvolvimento a custos elevados. A indústria não assume por si todos os riscos que gravitam esse tipo ação, pretendendo então socializá-los (Mazzucato, 2013).

A terceira pergunta de análise estratégica versa sobre os determinantes do escopo do produto ou serviço de uma firma. A análise concentra-se sobre os esforços de integração de cadeias e diversificação da produção. Na perspectiva da organização industrial, a integração de cadeias produtivas para frente e para trás qualifica o produto entregando mais valor ao mercado. Porém, na visão de Porter (1998), a integração das cadeias via clusters é mais vantajosa do que as integrações verticais, pois induz competitividade. $\mathrm{Na}$ visão de recursos, a integração potencializa capacidades especiais das firmas. Baseia-se para tanto que há sinergias especiais entre indústrias e produtos (Peng et al., 2009). A esse último aspecto, considerando a capacitação tecnológica inovadora, que permite criar, modificar ou aperfeiçoar produtos e processos (Silvestre \& Dalcol, 2007) como recursochave, as complementaridades relacionadas ao processo inovativo são mais facilmente obtidas entre empresas próximas.
Malerba (1999) enfatiza o relacionamento entre firmas e instituições, incluindo aí as organizações extra firma, tais como universidades e centros de pesquisa pública, pois são importantes fontes de inovação e mudança de muitos setores. Os vínculos aí estabelecidos, bem como as complementaridades entre firmas afetam suas estratégias e desempenho, bem como a taxa e direção das mudanças tecnológicas.

Vaydia (2011) observa que os benefícios de alianças estratégicas, a exemplo das redes de interação estabelecidas nos clusters, estão relacionados a menores custos de tecnologia, compartilhamento de riscos em projetos de alto risco, habilidade para atingir economias de escopo e escala em atividades de valor agregado, acesso à tecnologia, conhecimento e processos proprietários do aliado, e a criação e uma base para futura competição na indústria nos termos de uma vantagem competitiva sustentável.

Por fim, indaga-se sobre a natureza do sucesso das firmas. Para a visão industrial, o grau de competitividade em uma indústria determina sobremodo o desempenho das firmas (Porter, 1998). Em Barney (1991), são as capacidades específicas das firmas que determinam as diferenças de performance. Para a visão baseada em instituições em Peng (2009), é difícil imaginar que empresas operando globalmente ou localmente possam ser exitosas sem conhecer todas as regras do jogo, formais e informais.

Então, a análise sobre o papel das instituições na promoção do desenvolvimento econômico permite as seguintes proposições: (P1) o setor público exerce papéis relevantes para o desenvolvimento econômico e bem estar geral da sociedade, pois segundo Porter (1998), as instituições atuam na estabilidade macroeconômica e política, reduzindo riscos e incertezas para o fluxo produtivo de capitais, atua na eficiência e qualidade dos recursos utilizados pelas empresas, nos termos de uma mão-de-obra bem qualificada, infraestrutura física adequada e o fornecimento acurado de informações econômicas para os tomadores de decisão; (P2) o incentivo à competitividade entre as empresas inclui uma política de impostos e leis de propriedade intelectual que encorajem o investimento produtivo o que corrobora que o mercado não é suficientemente dinâmico do ponto de vista inovativo para operar sem este apoio institucional.

Preconiza-se, portanto, que um modelo explicativo para o processo inovativo, e por conseguinte, para o desempenho das firmas, não pode prescindir do papel relevante das instituições e organizações extra firma, induzindo uma modificação do modelo inicial proposto por Silvestre e Dalcol (2007). 


\subsection{O Modelo Híbrido de Silvestre e Dalcol}

Conforme observado na Figura 1 a seguir, para a explicação da formação da aglomeração industrial do setor estudado nesta pesquisa, são combinados elementos da abordagem de Cluster, representativa da visão baseada em indústria, com elementos da abordagem de sistemas de inovação, representativa da visão baseada em recursos, em que as visões se complementam e são suficientes para explicar o processo de formação do aglomerado e a dinâmica inovativa do setor.

No que diz respeito à abordagem de Cluster, tomando por base os estudos realizados no aglomerado industrial de Campos-RJ, Silvestre e Dalcol (2007) observaram que as vantagens oriundas da proximidade do ponto de vista da criação de inovação e de sua difusão, não surgem de maneira autônoma. Nesse sentido, o conhecimento, as tecnologias e os processos são direcionados para as firmas mais preparadas para absorvê-los. Adicionalmente, não propõem um mecanismo para a promoção dessa difusão e apropriação. Pretendem resolvê-lo tomando por base elementos estabelecidos nos sistemas de inovação, sejam tecnológicos (Carlsson, 1995) ou setoriais (Malerba,1999), pontuando os relacionamentos intra e intersetoriais entre firmas, os sistemas de conhecimento (Bell \& Albu, 1999) e as capacitações existentes e necessárias.

Observa-se, ainda, que embora a participação da Petrobras, instituição de capital misto que possui o governo como sócio majoritário, seja referenciada como fundamental para a promoção da aludida dinâmica, sua influência decisiva na formação e na dinâmica do aglomerado não é apresentada no modelo híbrido.
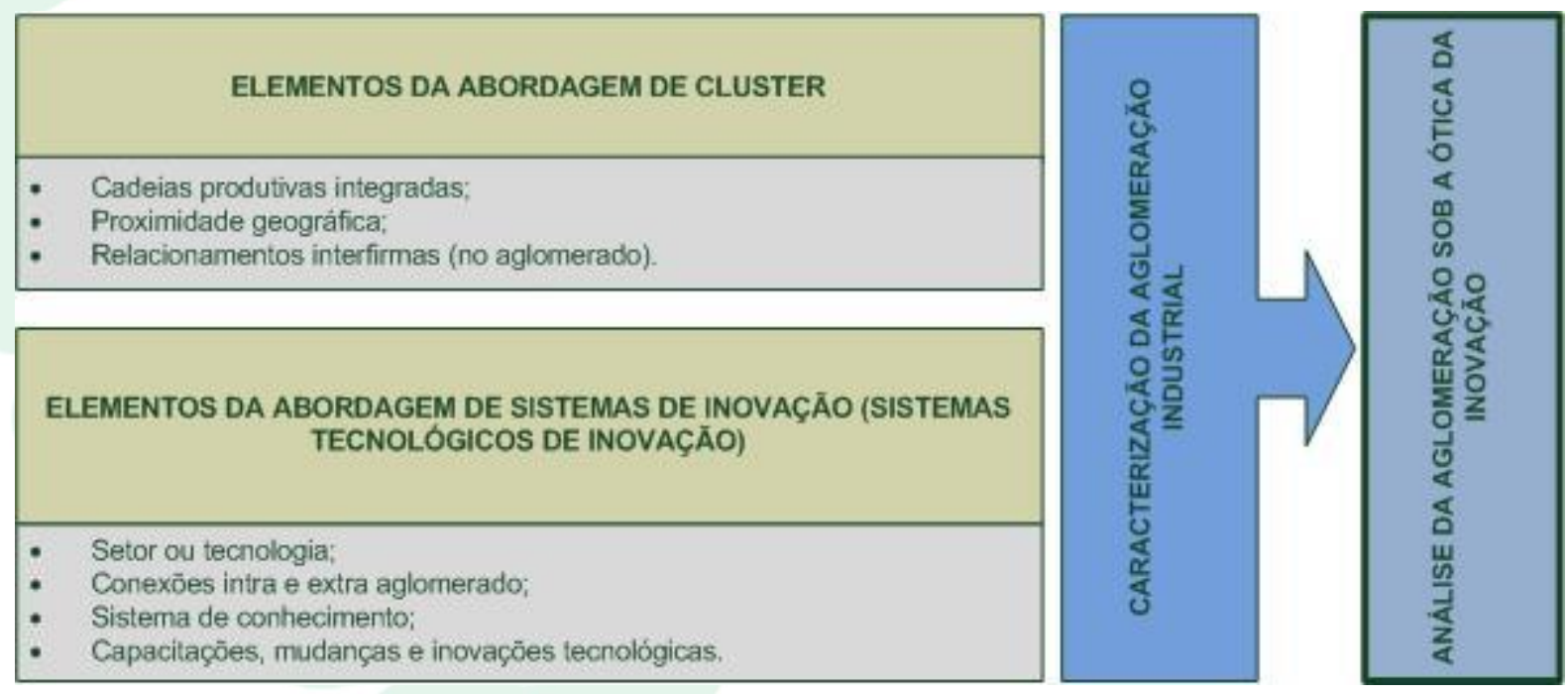

Figura 1 - Modelo Híbrido de Silvestre e Dalcol. Fonte: Silvestre e Dalcol (2007).

\subsection{O Modelo Híbrido Ajustado}

À semelhança do modelo híbrido proposto por Silvestre e Dalcol (2007), procurou-se ajustar as abordagens teóricas mencionadas dentro de um modelo prospectivo. Para cada uma das abordagens em questão, quais sejam a visão baseada em indústria mediante a teoria dos clusters (Porter, 1998), a visão baseada em recursos (Barney, 1991), o foco nos sistemas setoriais de inovação (Malerba,1999) e a visão baseada em instituições (Peng et al., 2009), foram criadas dimensões representativas do modelo. 


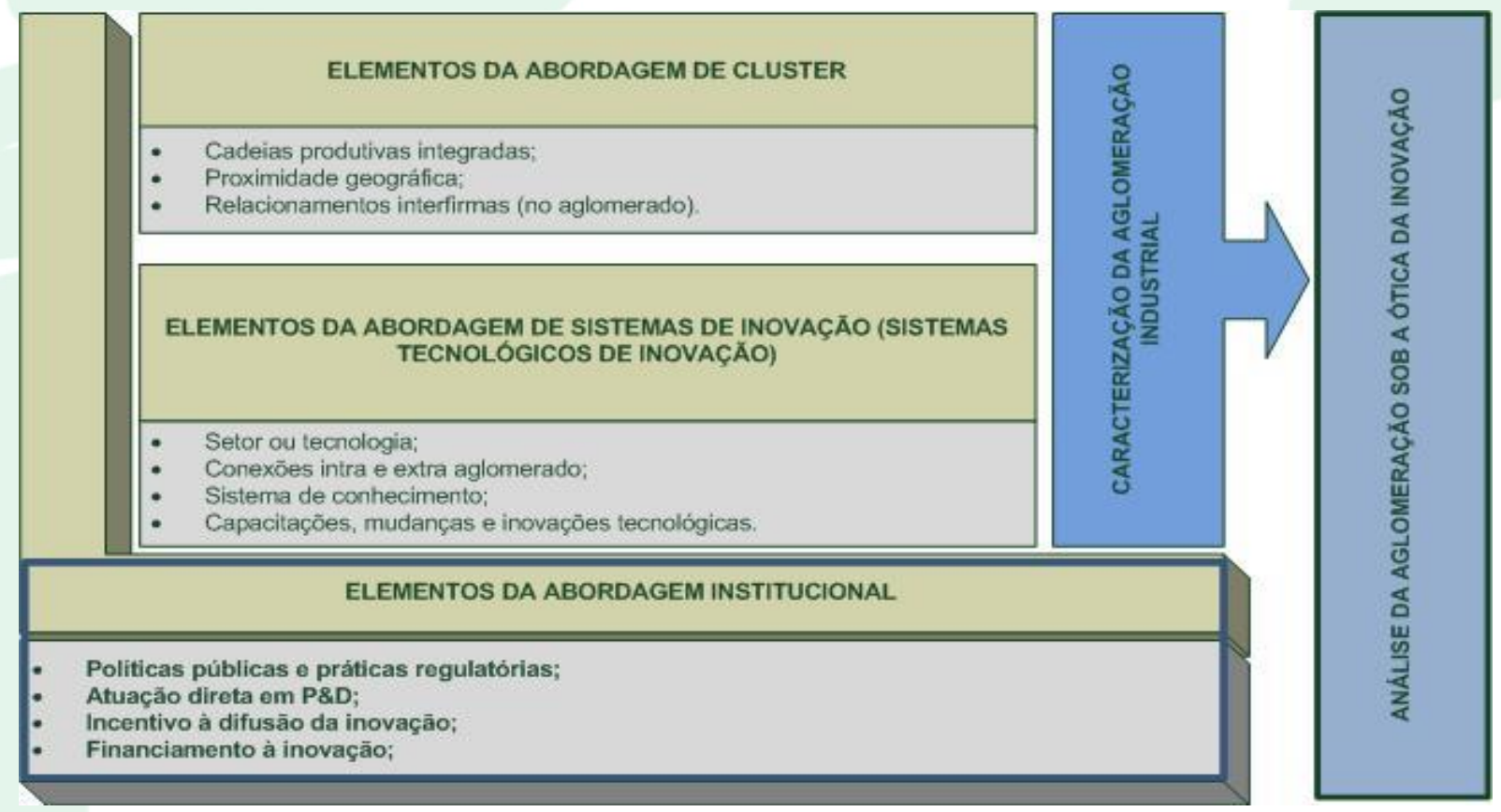

Figura 2- Modelo Híbrido Ajustado. Fonte: Autores (2014).

A primeira dimensão utilizada, representativa da abordagem de clusters, é o Nível de Cooperação Empresarial para Inovação. A segunda dimensão escolhida representativa da abordagem de sistemas de inovação é a Postura Tecnológica das Firmas. A terceira dimensão, representativa da abordagem institucional, é o Apoio Institucional ao Processo Inovativo. A respeito dessa última dimensão, apresenta-se como a base que sustenta os demais elementos do modelo, atuando de maneira indireta na promoção da inovação (Patanakul \& Pinto 2014).

\section{METODOLOGIA}

Assume-se a pesquisa como descritiva e qualitativa, com uso de técnicas de análise de conteúdo e estatísticas descritivas simples (Cooper \& Schindler, 2008; Jung, 2004). O trabalho foi realizado com duas linhas de atuação, uma de natureza teórica, em que se procurou corroborar a importância da participação das instituições e organizações públicas governamentais ou não para o incentivo à geração e difusão de inovação a partir das diversas linhas de pensamento estratégico existentes visando complementar o modelo teórico proposto por Silvestre e Dalcol (2007).

A segunda linha de atuação, de natureza empírica, utilizou dados da Pesquisa de Inovação do IBGE - PINTEC, ano base 2012. Para esse estudo, foram selecionadas informações sobre os setores caracterizados na Classificação Nacional de Atividades Econômicas [CNAE 2.0], em sua seção C, Indústria de Transformação, o primeiro setor na divisão 10, Fabricação de Produtos Alimentícios - IAP, e o segundo na divisão 14, Confecção de Artigos do Vestuário e Acessórios - IVA. A estratégia em questão visa observar, mediante os dados comparativos dos dois setores, o efeito das dimensões estratégicas do modelo sobre o processo inovativo, e por conseguinte, sobre o desempenho empresarial. A fim de localizar o estudo, foram consideradas informações da Pintec (2013) dos dois setores no estado do Ceará.

Para efeito de contextualização sobre o tamanho dos setores escolhidos, o número vínculos empregatícios é de 54.745 para a indústria de confecções e 33.494 para a indústria de alimentos, com o número de estabelecimentos com 3.265 para a indústria de confecções e 1.441 para a indústria de alimentos da Relação Anual de Informações [RAIS] do Cadastro Geral de Empregados e Desempregados [CAGED] (RAIS/CAGED, 2013). Observa-se, ainda, que o setor IVA está organizado em um arranjo produtivo local bem estabelecido no polo de confecções de Fortaleza (VIANA, 2009).

Ambos os setores evidenciados na Pintec (2013) são classificados como BeMB, de baixa e média-baixa tecnologia, na medida em que se constituem agentes difusores de inovações desenvolvidas por outras 
indústrias, em especial aquelas com classificação MAeA, média-alta e alta tecnologia, enfatizando o aspecto cooperativo do processo de inovação industrial (OCDE, 2003). Esta classificação os nivela quanto à criação e utilização de inovação.

A Pintec (2013, p. 5) define Inovação Tecnológica como sendo a "introdução no mercado de um produto (bem ou serviço) que seja novo ou substancialmente aprimorado pelo menos para a empresa, ou pela introdução na empresa de um processo que seja novo ou substancialmente aprimorado, pelo menos para a empresa". Conceitua também Atividade Inovativa como sendo esforços empreendidos pela empresa no desenvolvimento e na implementação de produtos (bens ou serviços) e processos novos ou aperfeiçoados. A pesquisa procura mensurar estes esforços por meio de uma escala de importância para a empresa e em termos monetários, por meio de estimativa dos dispêndios nestas atividades. Nesta pesquisa foram associados os referidos conceitos às noções de capacitação tecnológica inovativa e de capacitação tecnológica rotineira oriundas das teorias de sistemas de inovação descritas em Silvestre e Dalcol (2007).

As informações foram tabuladas a partir do questionário da Pintec (2013) nos campos relacionados aos capítulos Atividades Inovativas e Fontes de Inovação.

A parte do questionário que trata das Atividades Inovativas é precedida pelo texto: assinale a importância das atividades desenvolvidas pela empresa para a implementação de produtos e ou processos novos ou significativamente aperfeiçoados, no período entre 2009 e 2011. Foram sugeridos os tipos de atividades listadas na Figura 3. Na coluna direita, constam as categorizações assumidas no modelo Silvestre e Dalcol (2007) para a Postura da Firma em Relação à Tecnologia. Ambas as colunas mantêm correspondência.

\section{Atividades Sugeridas na Pintec 2012}

Aquisição de outros conhecimentos externos

Aquisição de software

Aquisição de máquinas e equipamentos

Treinamento

Aquisição externa de Pesquisa

Desenvolvimento

Projeto industrial e outras preparações técnicas

Introdução das inovações tecnológicas no mercado

\section{Postura Tecnológica das Firmas}

Apenas Usuários

Apenas Usuários

Apenas Usuários

Apenas Usuários

Adaptações Menores

Adaptações de Projeto

Capaz de Inovar

Figura 3 - Atividades Inovativas e Postura das Firmas - correspondência.

Fonte: Pesquisa de campo (2014).

A dimensão Postura Tecnológica das Firmas, representativa da abordagem de Sistemas de Inovação descreve a forma como a empresa utiliza a tecnologia a partir de suas atividades produtivas. Procurou-se inferir dos dados fornecidos pela pesquisa quatro tipos diferentes de posturas a saber, apenas usuária de tecnologia, no sentido de que importa a tecnologia, incorporando-a ao seu processo produtivo sem uma compreensão maior sobre ela; capaz de realizar adaptações de menor significância tecnológica, em função do pequeno domínio que exerce sobre a tecnologia; capaz de ajustar o projeto industrial à nova realidade tecnológica; capaz de inovar, em que domina a tecnologia a ponto de introduzir as inovações tecnológicas no mercado. No que diz respeito às adaptações menores, assume-se que a aquisição externa de P\&D habilita a empresa a realizar pequenos ajustes tecnológicos.

A sessão do questionário que trata das Fontes de Informação é precedida pelo texto: indique a importância atribuída a cada categoria de fonte de informação empregada entre 2009 e 2011, para o desenvolvimento de produtos (bens ou serviços) e ou processos novos ou substancialmente aprimorados. A Figura 4 explicita a classificação proposta pela pesquisa do IBGE e sua associação com o Tipo de Fonte de Informação, indicativo da dimensão Apoio Institucional ao Processo Inovativo. Observou-se para esta classificação somente o apoio institucional não financeiro. As instituições participam da aglomeração e podem ou não ter natureza governamental. 


\begin{tabular}{|l|l|}
\hline \multicolumn{1}{|c|}{ Fontes de Informação } & $\begin{array}{c}\text { Apoio Institucional } \\
\text { ao Processo } \\
\text { Inovativo }\end{array}$ \\
\hline Departamento de P\&D & Interna \\
Outras Áreas & Interna \\
Outra Empresa do Grupo & Interna \\
Fornecedores & Mercado \\
Clientes ou Consumidores & Mercado \\
Concorrentes & Mercado \\
Empresas de Consultoria de Consultores Independentes & Instituição \\
Universidades ou Outros Centros de Ensino Superior & Instituição \\
Institutos de Pesquisa ou Centros Tecnológicos & Instituição \\
Centros de Capacitação Profissional e Assistência Técnica & Instituição \\
Instituições de Testes, Ensaios e Certificações & Instituição \\
Conferências Encontros e Publicações Especializadas & Instituição \\
Feiras e Exposições & Instituição \\
Redes de Informação Informatizadas & Instituição \\
\hline
\end{tabular}

Figura 4 - Fontes de Cooperação e Natureza Institucional da Cooperação.

Fonte: Pesquisa de campo (2014).

A dimensão Nível de Cooperação Empresarial para Inovação, representativa da teoria dos clusters é tratada pelo capítulo Fontes de Inovação da Pintec (2013). Descreve a importância das fontes de informação que a empresa utilizou para o desenvolvimento dos produtos e ou processos novos ou substancialmente aprimorados. O nível de cooperação é medido pela importância da informação obtida para o processo inovativo. Somente foram consideradas fontes externas quais sejam, Fornecedores, Clientes ou Consumidores, Concorrentes, Consultorias, Universidades e Centros de Capacitação Profissional, Publicações e Eventos da Área, e Redes de Informação Informatizadas. Houve nesse quesito uma adaptação às categorias propostas por Silvestre e Dalcol (2007), sem prejuízo do entendimento proposto pelo modelo. Assim, assume-se que o nível de conexão entre as empresas é dado pela importância das contribuições realizadas pelas múltiplas fontes. Quanto mais importantes as contribuições, mais conectadas as empresas. Foram considerados os níveis Alto (Conexão Alta), Médio (Conexão Média) e Baixo (Conexão Baixa).

Para efeito de coleta e aferição dos resultados, foram considerados dois setores industriais medidos pela Pintec (2013). O primeiro setor, unidade de análise para corroboração do modelo proposto, é o setor de Confecção de Artigos do Vestuário e
Acessórios tabulado pela pesquisa. O segundo setor, utilizado para fazer o contraponto de análise, trata-se do setor de Fabricação de Produtos Alimentícios. Para cada um dos setores industriais considerados, foram comparados os valores para as dimensões acima tratadas.

\section{RESULTADOS E DISCUSSÃO}

Inicia-se a avaliação dos resultados da pesquisa apresentando os histogramas comparativos dos setores para cada uma das dimensões analisadas. Consideraram-se o Setor 1 como o de Confecção de Artigos do Vestuário e Acessórios - IVA e o Setor 2 como o de Fabricação de Produtos Alimentícios - IAP.

a) Dimensão Postura da Firma em Relação à Tecnologia

No gráfico a seguir, as atividades de inovação sugeridas pela Pintec (2013) são mapeadas à postura da firma em relação à tecnologia nos seguintes termos:

- USU: Apenas Usuários;

- MEN: Adaptações Menores;

- PROJ: Adaptações de Projeto;

- INO: Capaz de Inovar. 


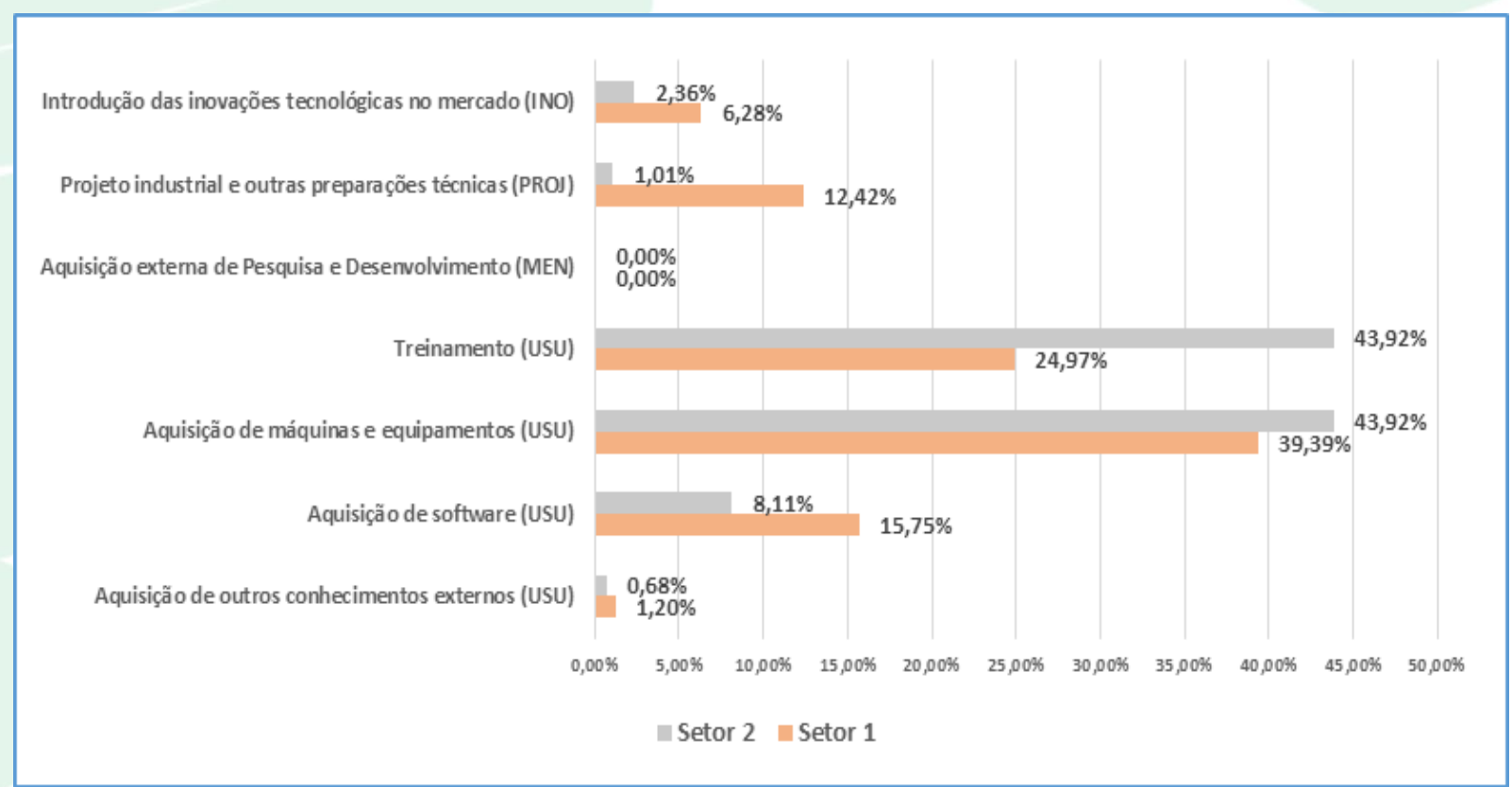

Figura 5 - Atividades e Inovação versus Postura das Firmas em Relação à Tecnologia. Fonte: Pintec (2013).

Para efeito de melhor comparação entre os dois setores, segue na Figura 6 uma visão consolidada da Figura 5.

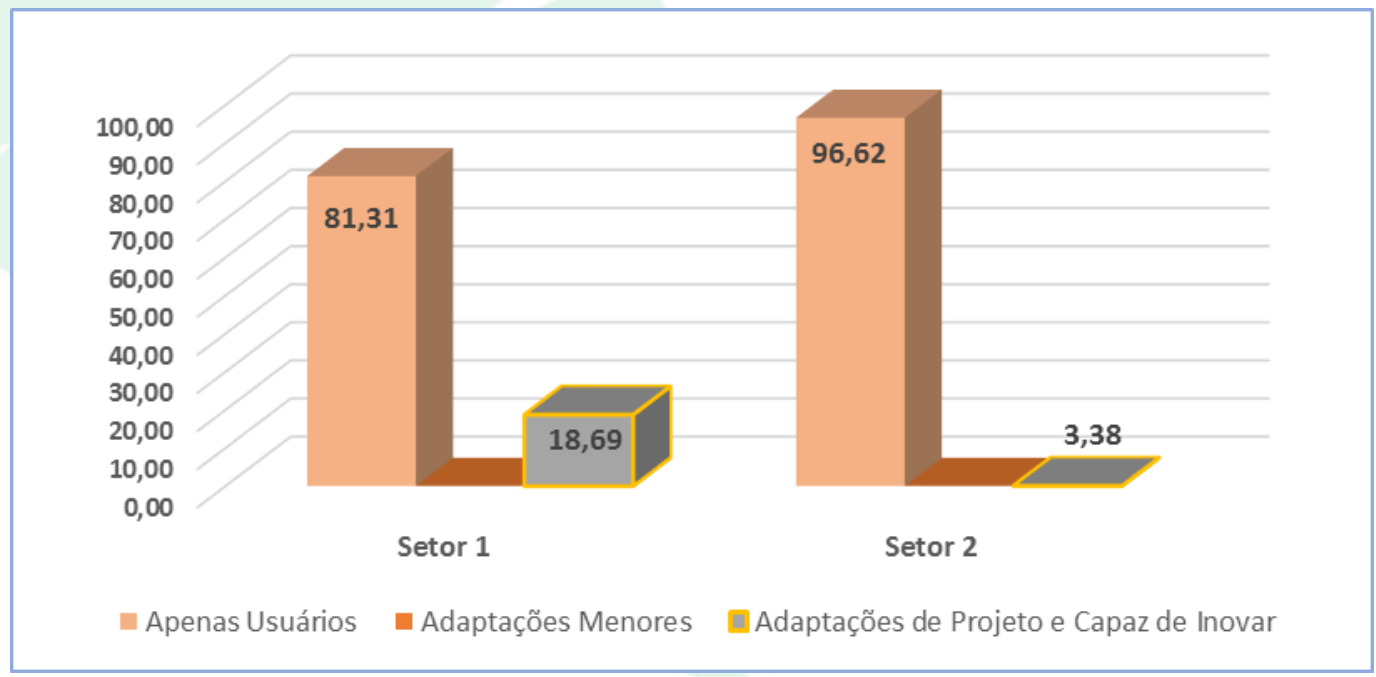

Figura 6 - Abrangência da Atividade Inovativa.

Fonte: Pintec (2013).

Em relação à Figura 6, observa-se uma capacidade de inovar maior no Setor $1(18,69 \%$ de todas as atividades) comparativamente ao Setor 2 (3,38\% de todas as atividades). Essa predominância denota o maior potencial deste setor em criar e utilizar novas tecnologias físicas. Considerando Barney (1991), o processo de inovação, criação de tecnologia e o uso produtivo necessitam de recursos socialmente complexos. A força da rede de relacionamentos existente no Setor 1, no âmbito do cluster formal em que se estrutura e que alude à complexidade dos recursos envolvidos é demonstrada claramente pelo maior percentual de atividades inovativas de importância alta neste setor, informação corroborada pelo Gráfico 5 adiante.

Ainda em relação à Figura 6, observa-se que ambos os setores apresentados são predominantemente $\mathrm{BeMB}$, de baixa e média-baixa tecnologia, na medida em que se constituem agentes difusores de inovações desenvolvidas por outras indústrias. Essa informação é 
demonstrada pelo alto nível de atividades inovativas em que se inserem como "apenas usuários" de todas as atividades.

b) Dimensão Apoio Institucional ao Processo Inovativo

Na Figura 7, as fontes de cooperação sugeridas pela Pintec (2013) são mapeadas à natureza da fonte nos seguintes termos:
- INST: Fonte Institucional;

- MER: Fonte de Mercado - Forças de Porter (1998);

- INT: Fonte Interna.

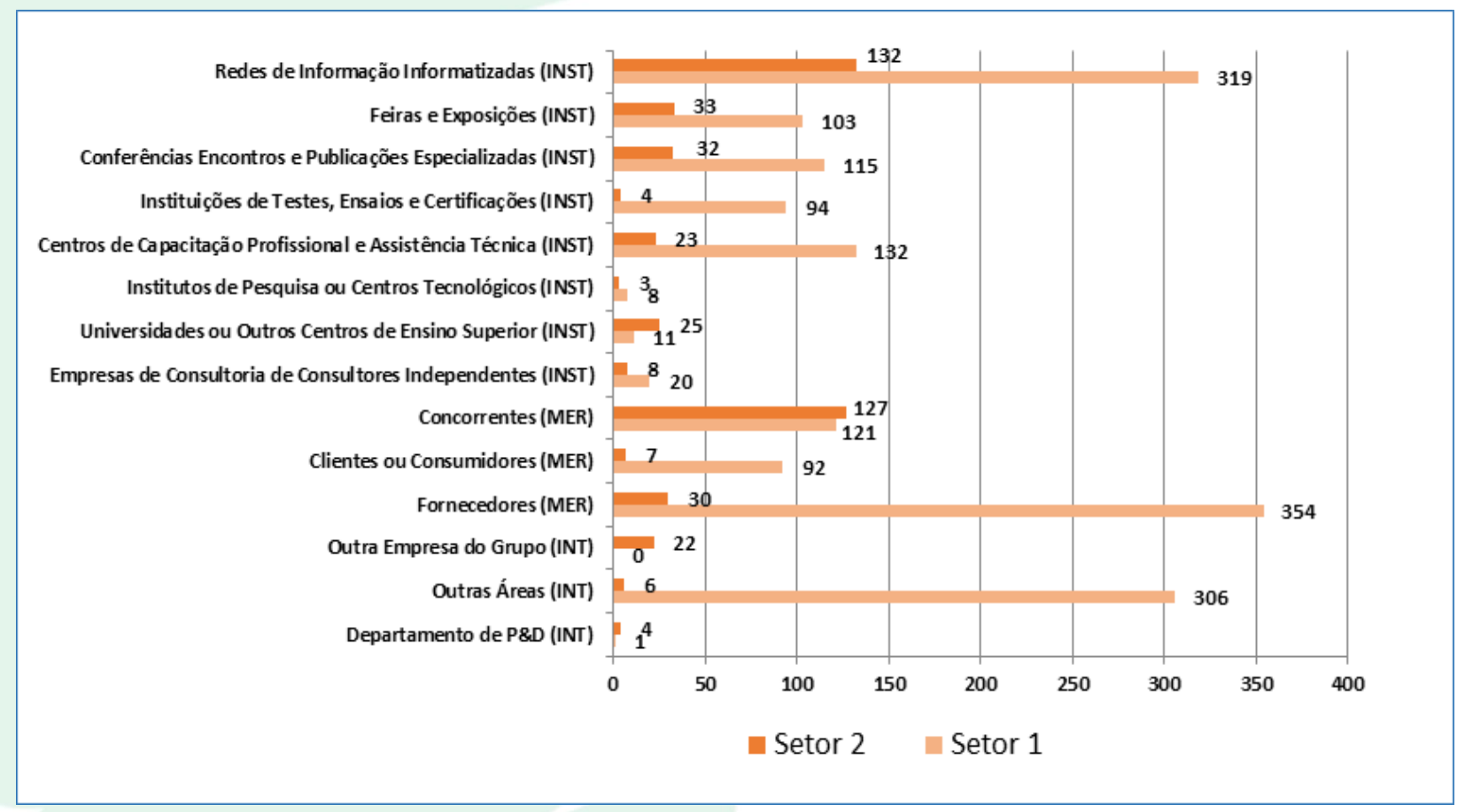

Figura 7 - Eventos de Inovação por Fonte. Fonte: Pintec (2013).

A Figura 8 a seguir expõe a informação que corrobora o objetivo geral deste trabalho, relacionado à importância das instituições "extra firma" no apoio a eventos de inovação. Em ambos os setores estudados, o apoio dessas instituições foi responsável direta ou indiretamente por cercada metade de todas as atividades inovativas. 


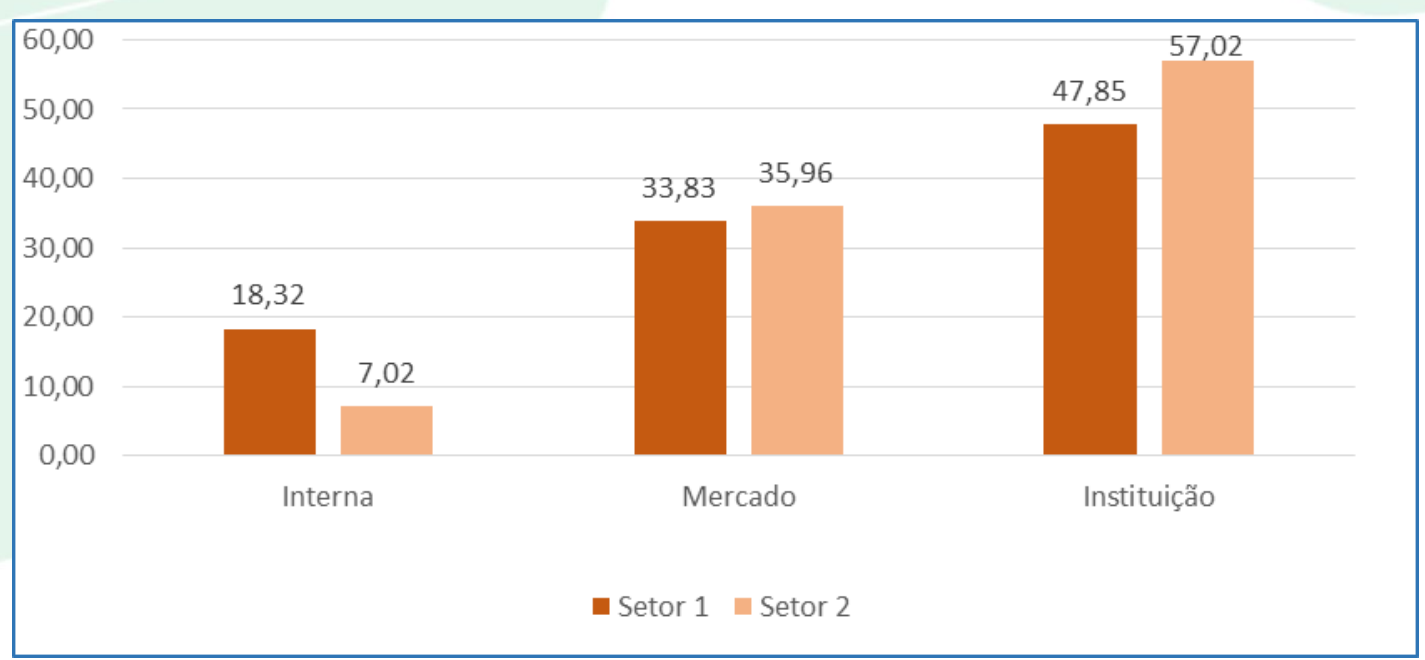

Figura 8 - Participação Relativa dos Eventos de Inovação por Tipo de Fonte.

Fonte: Pintec (2013)

Do ponto de vista institucional, observa-se que a maior parte dos eventos inovativos tem formação nas instituições que gravitam o ambiente estudado. Evidenciou-se que $47,85 \%$ para o setor de vestuários e $57,02 \%$ para as IAP, de todos os eventos de inovação são provenientes de instituições participantes das cadeias produtivas, o que corrobora com a proposição P2 de que o mercado não é suficientemente dinâmico do ponto de vista inovativo para operar sem este apoio institucional.

Vale também observar na Figura 8 que o nível de conhecimento sobre as tecnologias utilizadas nos setores é diferenciado, fato este demonstrado a partir da produção interna de eventos de inovação. Observa-se que $18,32 \%$ desses eventos no setor de vestuário são realizados internamente, contra $7,02 \%$ no setor de alimentos processados, o que reforça o dinamismo inovativo do setor em relação ao IAP. Esse menor dinamismo inovativo desse setor é compensado por uma presença institucional quando comparado ao IVA.
A informação da Figura 8 também atende ao objetivo geral do trabalho. Um modelo que não apresente de forma explícita a participação institucional "extra firma" como preponderante para a geração de eventos de inovação, não possui um poder explicativo forte para o processo de criação e difusão tecnológica, principalmente em regiões mais carentes de dinamismo mercadológico como é o caso dos dois setores no estado do Ceará. No caso presente, a grande maioria dos eventos de inovação em ambos os setores são provenientes de iniciativas institucionais.

Vale ressaltar que o nível de investimento do setor público para promoção da inovação não se mostrou importante pela Pintec (2013) conforme a Tabela 2 a seguir, e que políticas seletivas e específicas do setor público a partir de programas bem estruturados de investimento direto e incentivo ao capital de risco podem alavancar mais ainda o papel das instituições na promoção da inovação (Keller \& Block, 2012).

Tabela 2 - Fontes de Financiamento por Setor.

\begin{tabular}{|c|c|c|c|c|}
\hline \multirow{2}{*}{ Fontes de Financiamento } & \multirow{2}{*}{$\begin{array}{c}\text { Total de } \\
\text { Eventos }\end{array}$} & Total & Privado & Público \\
\cline { 3 - 5 } & & & & 5 \\
\hline $\begin{array}{c}\text { Confecção de artigos do } \\
\text { vestuário e acessórios }\end{array}$ & .563 & 6 & & 3 \\
\hline $\begin{array}{c}\text { Fabricação de produtos } \\
\text { alimentícios }\end{array}$ & .474 & 3 & & 3 \\
\hline
\end{tabular}

Fonte: Pintec (2013) 
c) Dimensão Nível de Cooperação Empresarial para Inovação

Na Figura 9, o Nível de Cooperação é medido pela importância dos eventos de inovação para os setores considerados. Há uma relação direta entre o impacto de inovações produzidas dentro do setor por outras firmas, medido aqui pela importância dos eventos inovativos, e o nível de cooperação empresarial. Quanto maior o impacto intrafirma, maior a importância do evento inovativo e maior o nível de cooperação para a inovação.

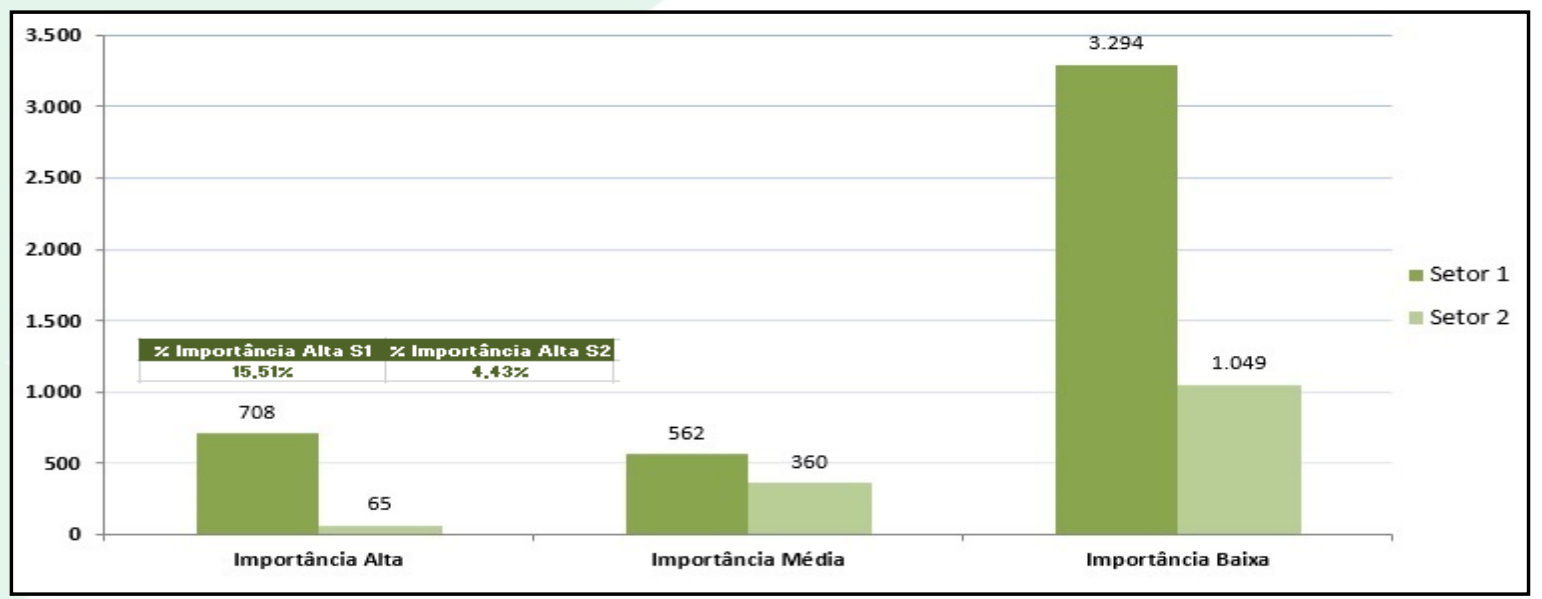

Figura 9 - Importância da Cooperação para Inovação.

Fonte: Pintec (2013)

Enquanto no Setor 1 (S1), Confecção de artigos do vestuário e acessórios, $15 \%$ dos eventos de inovação são considerados importantes pelas empresas, no Setor 2 (S2), apenas 4\% destes são considerados relevantes. Esse maior nível de importância dos eventos de inovação no $\mathrm{S} 1$ está relacionado à conformação em cluster do setor IVA, condicionado pelo apoio institucional forte já demonstrado anteriormente.

\section{CONCLUSÃO}

Observou-se que o modelo de Silvestre \& Dalcol (2007) uma possível falha na explicação da origem do processo inovativo no aglomerado petrolífero de Campos por não considerar o importante efeito da participação institucional na criação e difusão de inovações. Embora trate de duas dimensões relevantes dentro do processo inovativo, quais sejam a influência de fatores relacionados à organização industrial e à forma específica de utilização da inovação pelas firmas, o Modelo Híbrido não foi capaz de registrar os importantes efeitos que instituições exercem sobre o processo inovativo. A lacuna fica mais evidente no âmbito de localidades pouco maduras do ponto de vista do funcionamento do mercado.

$\mathrm{O}$ objetivo geral que norteou o trabalho visou investigar a influência institucional para a criação de inovação e modificação do perfil de utilização da tecnologia. Nesse sentido, observou-se que as fontes institucionais de eventos inovativos são muito variadas, constituídas dentre outras por redes de informações, conferências, centros de testes e certificações, centros de formação profissional e universidades. As organizações tidas como institucionais funcionando em um ambiente que fomenta o processo inovativo induz a criação e a utilização de recursos socialmente complexos à luz da definição de Barney (1991), e portanto, são fontes de vantagem competitiva sustentável para as firmas dos setores estudados. À medida que há um maior relacionamento entre as firmas dentro do processo inovativo, o perfil de utilização da tecnologia se altera, resultando em um aproveitamento mais qualificado das novas tecnologias.

Por fim, objetivando complementar a visão parcial dos autores do Modelo Híbrido de explicação do processo inovativo no âmbito de arranjos produtivos localizados, este artigo propôs um modelo alternativo, Modelo Híbrido Ajustado. O referido modelo salientou os papéis relevantes da atuação institucional na criação e difusão de inovação, representados pela dimensão Elementos da Abordagem Institucional. $O$ modelo proposto foi então aplicado à análise do processo inovativo nos setores IVA e IAP, demonstrando o papel crucial desenvolvido pelas instituições de apoio àqueles setores.

A utilização de dados secundários para corroborar o papel institucional na conformação do modelo de referência, modelo híbrido, principalmente 
Influência Institucional em Arranjos Produtivos Locais para Criação de Inovação

no nível de agregação considerado para a análise, mostrou-se difícil, principalmente quando houve o mapeamento das dimensões consideradas no referido modelo e os resultados da Pintec (2013). Para estudos futuros, os autores sugerem a utilização de pesquisas de campo em que as firmas componentes de cada setor poderiam explicitar de forma mais clara a natureza dos eventos inovativos e os efeitos reais dentro de suas cadeias produtivas.

\section{REFERÊNCIAS}

Amin, A.(1999). An institutionalist perspective on regional economic development. International Journal of Urban and Regional Research, London, 23(2), 365-378.

Amin, A; Thrift, N.(1992). Neo-Marshallian nodes in global networks. International Journal of Urban and Regional Research, London, 16 (4), 571-587,

Ashford, N. A. (2000). An innovation-based strategy for a sustainable environment. In: J.Hemmelskamp, K. Rennings, \& F. Leone (Eds.), Innovationoriented environmental regulation Theoretical approach and empirical analysis (p. 67-107). New York/Berlin: Springer-Verlag.

Barney, J. (1991).Firm resources and sustained competitive advantage. Journal of Management, Charlotte NC, 17 (1), 99-120.

Bell, M.; Albu, M. (1999).Knowledge systems and technological dynamism in industrial clusters in developing countries. World Development, Montreal, 27 (9), Sept., 1715-1914.

Bossink, B.A. G. (2002). A Dutch public-private strategy for innovation in sustainable construction. Construction.Management and Economics, Amsterdam, 20 (7),633-642.

Brito, E. P. Z; Brito, L. A. L; Porto, E. C; Szilagyi, M. E.(2010). A Relação entre aglomeração produtiva e crescimento: a aplicação de um modelo multinível ao setor industrial paulista. Revista de Administração Contemporânea, Rio de Janeiro, v. 14, n. 4, p. 615-632.

Camagni, R.(1991). Local 'milieu', uncertainty and innovation networks: towards a new dynamic theory of economic space. In: CAMAGNI, R. (Ed). Innovation networks: spatial perspectives. London: Belhaven Press, 121-142.

Carlsson, B. (1995).Technological systems and economic performance: the case of factory automation.Dordrecht: Kluwer.
Cassiolato, J. \& Lastres, H. (2003). Novas políticas na era do conhecimento: o foco em arranjos produtivos e inovativos locais. Revista Parcerias Estratégicas, Brasília,v.1, n. 17,set., p. 5-29.

Cnae 2.0. (2014). Tabela P2011_H1_Ceara. Disponível em <http://www.cnae.ibge.gov.br/estrutura.asp. $>$.Acess adoem 03/06/2014.

Cooper, D. R., \& Schindler, P. S. (2008). Métodos de pesquisa em Administração (7a ed.). São Paulo: Bookman.

D’Aveni, R.A. (1994). Hypercompetition: Managing the dynamics of strategicmaneuvering.New York: The Free Press.

Dimaggio, Paul J.; Powell, Walter W. (2007). A jaula de ferro revisitada: isomorfismo institucional e racionalidade coletiva nos campos organizacionais. In: CALDAS, Miguel P.; Bertero, Carlos Osmar (Coords.).Teoria das Organizações. São Paulo: Atlas.

Edquist. C; Björn, J. (1997).Institutions and organizations in system of innovation. In: Charles Edquist, Org. Systems of Innovation: Technologies, Institutions and Organizations. London: Routledge.

Freeman, C. (1995).The national systems of innovation. In:Historical perspective. Cambridge Journal of Economics, Cambridge, 19 (1), Feb, 524 ,

Hansen, P. B; Oliveira, L. R.(2009).Proposta de modelo para avaliação sistêmica do desempenho competitivo de arranjos produtivos:o caso do arranjo coureiro-calçadista do Vale dos Sinos (RS - Brasil). Produto \&Produção, Porto Alegre, v. 10, n. 3, p. 61-75.

Keller, Matthew R.; Block, Fred. (2013). Explaining the transformation in the US innovation system: the impact of a small government program. SocioEconomic Review, Oxford University Press and the Society for the Advancement of Socio-Economics, doi: $10.1093 / \mathrm{ser} / \mathrm{mws} 021,11$ (4), 629-656. Jung, C. F. (2004). Metodologia para pesquisa \& desenvolvimento: aplicada a novas tecnologias, produtos e processos. Rio de Janeiro: Axcel Books.

Link, A. N., \&Scott, J. T. (2010). Government as entrepreneur: Evaluating the commercialization success of SBIR projects. Research Policy, London, v. 39, n. 5,p. 589-601.

Malerba, F. (1999).Sectoral systems of innovation and production. Research Policy,London, 31 (2),p. $247-$ 264. 
Mazzucato, Mariana.(2013). The Entrepreneurial State: Debunking Public vs. Private Myths in Risk and Innovation (Anthem Other Canon Economics) [EBook Kindle], May.

Mascena, K.M.C. De,; Figueiredo, F.C.; Boaventura, J.M.G. (2013).Clusters e APL's: Análise bibliométrica das publicações nacionais no período 2000 a 2011. Revista de Administração de Empresas - RAE, São Paulo, v. 53, n. 5, p. 454-468. Nelson, R. R. Rosenberg, N. (1993).National innovation systems: A comparative analysis. New York: Oxford University Press.

Newlands, D.(2003).Competition and cooperation in industrial clusters: the implications for public policy. European Planning Studies, London, 11 (5), 521-532.

Patanakul, Peerasit; Pinto, Jeffrey K. (2014). Examining the roles of government policy on innovation. Journal of High Technology Management Research, London,25 (2), 97-10.

Peng, M.W. et al. (2009). The institution-based viewas a third legfor a strategy tripod. Journal Academy of Management Perspectives,Dallas,23(3), 63-81.

Pintec. Pesquisa de Inovação. (2013). Instruções para o preenchimento do questionário. Rio de Janeiro:
IBGE, 2013. Disponível em <http://www.pintec.org.br>. Acessado em 12.05 .2013

Porter, M. E. (1998). Clusters and the new economics of competition. Harvard Business Review, in press.

Rais/Caged. (2013). Ministério do Trabalho e Emprego.Disponível em <portal.mte.gov.br/geral/estatisticas.htm>. Acessado em 16/03/2014.

Silvestre, B. S; Dalcol, P. R. T.(2007).Conexões de conhecimento e posturas tecnológicas das firmas: evidências da aglomeração industrial de petróleo e gás da Bacia de Campos. Gestão \&Produção, São Paulo, v. 14, n. 2, p. 221-238.

Souza, Enilvan M, et al. (2013). Inovação Como Mecanismo de Fuga do Isomorfismo Organizacional. Revista Gestão \& Tecnologia, Pedro Leopoldo, v. 13, n. 2, p. 72-93, mai./ago.

Vaydia, S. (2011).Understanding strategic alliances: an integrated framework.Journal of Management Policy and Practice, New York,12 (6),90-100.

Viana, Fernando L, E. (2009). Análise setorial Indústria do Vetuário, ETENE - Banco do Nordeste, dez. 